\title{
Geomagnetic polar observatories: the role of Concordia station at Dome C, Antarctica
}

\author{
Domenico Di Mauro ${ }^{1,}$, Lili Cafarella ${ }^{1}$, Stefania Lepidi ${ }^{1}$, Manuela Pietrolungo ${ }^{1}$, \\ Laura Alfonsi ${ }^{1}$, Aude Chambodut ${ }^{2}$ \\ ${ }^{1}$ Istituto Nazionale di Geofisica e Vulcanologia, Rome, Italy \\ ${ }^{2}$ École et Observatoire des Sciences de la Terre, Strasbourg Cedex, France
}

\author{
Article history \\ Received June 17, 2014; accepted December 22, 2014. \\ Subject classification: \\ Geomagnetic observatory, GNSS, Azimuth Mark Determination, Dome C, Concordia, Antarctica.
}

\begin{abstract}
A geomagnetic observatory is a permanent facility where magnetic declination and inclination are recorded in conjunction with the temporal evolution of the magnetic field components. Polar regions are scarcely covered by observational points then the contributions from observatories located there are particularly relevant. The geomagnetic observatory at Concordia station, Dome C-Antarctica is located in the inner part of the continent, its position is favorable for two key reasons, i) data are unaltered by the "coastal effect" and ii) crustal effect is negligible due to the thickness, almost $3 \mathrm{~km}$, of ice coverage. Nevertheless, these latter conditions imply an unconsidered aspect which characterizes the entire station and every structure laying on the ice surface: the dome on which Concordia station resides is sliding horizontally and moving vertically with a velocity of few millimeter to centimeters per year as indicated by independent geodetic observations. This slow and continuous movement has a puzzling effect on the trend of horizontal components of the magnetic field, sampled in a time window of a decade since the establishing of the observatory in 2005. During the International Polar Year (2007-2009) the observatory was upgraded with new equipment fulfilling the requirements of the Intermagnet consortium, and becoming an observatory member in 2011. In this paper are illustrated the strategy adopted to track any possible displacement of the observatory reference points (i.e. the azimuth mark, the pillar position) and all the ordinary and extraordinary actions required for collecting high quality data.
\end{abstract}

\section{Introduction}

The ensemble of geomagnetic observatories spread around our planet is aimed to mark out the temporal evolution and the spatial configuration of the Earth's magnetic field at different time-space scales. Observatory data enclose the superposition of natural sig- nals generated by different physical processes from the Earth's core to mantle, lithosphere, ocean, ionosphere, magnetosphere, and the solar-terrestrial interaction. Ideally, an even and dense coverage of observational points on the globe allows the computation of models of the geomagnetic field very close to the observed field, as the International Geomagnetic Reference Field (IGRF), adopted by the referenced community (http:/ / www.ngdc.noaa.gov/IAGA/vmod/igrf.html). This latter model, compiled and released every 5 years by the referenced community, is nothing more than a synthetic (mathematical) description of the field derived from the measured values collected continuously and for long time at each observatory. The possibility to expand the number of ground observatories, especially in scarcely covered areas like the polar regions, or modernize the existent obsolete instrumentation in pre-existent observatories should be one of the principal objective of the scientific community to accomplish the full understanding of the ongoing geodynamical processes both inside and outside the planet, from the Earth's core where the main field is generated to the field interactions with external sources. Since 2005, after 3 years of testing, a geomagnetic observatory is in operation on the iced plateau, at Dome C, Antarctica (geographic coordinate: $75^{\circ} 6^{\prime} 4^{\prime \prime} \mathrm{S} ; 123^{\circ} 19^{\prime} 51^{\prime \prime}$ E, elevation $3.232 \mathrm{~m}$ ). The observatory is currently maintained by two scientific institutions, INGV for Italy and EOST for France. Concordia station shares its facility between the two countries which agreed to establish and sustain a scientific base at Dome C since the beginning of 2000's; this statement became official in 2005 with the first 
winter-over. The position of the geomagnetic observatory at Dome $\mathrm{C}$ is particularly favorable since it is far from the electrical induction due to the conductive sea water coastal circulation and far from the effects of the crustal field contamination, a source of severe bias for those observatories located on magnetized basements. Another important aspect of the Dome C observatory is the location inside the polar cap, very close to the south invariant pole, and the geomagnetic pole, during the whole day. The invariant and geomagnetic poles are those points (small areas) around which the aurora ovals are generated and phenomena like magnetic storms, substorms and pulsations are enhanced and display strong variations within short distances [Akasofu 2002]. Hence, a denser networks of stations possibly with good instrumentation at both hemispheres would be of great support to a wide range of geophysical studies. Moreover the typical dipolar configuration almost parallel to the Earth's spin axis (tilted of about $11^{\circ}$ ) implies a strengthening of the magnetic field at polar regions, and then close to the poles the field intensity is two times the one at equatorial or low latitude areas. Data from the Concordia observatory are also valuable for global and regional modeling based on ground and satellite measurements and for representing an absolute constraint and reference for the measurement obtained from satellite dedicated to the Earth's magnetic field observation as for Swarm ESA mission launched on November 22nd, 2013, (http:// www.esa.int). Although the location of the Concordia observatory at Dome $\mathrm{C}$ is particularly favorable for the reasons described above, at the same time, the entire ice mass of the Antarctic plateau, including the eastern sector, and every permanent structure put on its surface, undergoes relevant local and global displacements, as revealed by integrated analysis through geodetic, glaciological, geophysical, and InSAR (INterferometric Synthetic-Aperture Radar) space-based surveys [Capra and Dietrich 2008, Rignot et al. 2008]. The sliding effect of the Antarctic plateau could in principle invalidate the observations made on the assumption of a steady geographical position. One of the requirements for a geomagnetic observatory is the conservation through time of a stable position, and consequently the possible effect of the local displacement at Dome $C$ needs to be adequately measured and considered when monitoring the long-trend changes on the horizontal components of the geomagnetic field. The unexpected rate of change in the horizontal component and the magnetic declination at Concordia in comparison with the known "secular variation" (Figure 1), more relevant since 2009 suggested that a possible cause to the anomalous long-term trend was the slow but continuous displacements of the structures hosting the observatory. The sliding was effectively demonstrated by independent geodetic observations made at Dome C by a GPS network established in 1995. The 37 observational points surrounding the Concordia station along concentric rings at increasing distances from 3 to $25 \mathrm{~km}$ pointed out that at the dome summit has an horizontal velocity of about $11 \mathrm{~mm} / \mathrm{yr}$ $\pm 0.6 \mathrm{~mm} / \mathrm{yr}$ along a direction of $302^{\circ}$ clockwise from true north $\left(\mathrm{V}_{\mathrm{N}}=5.8 \mathrm{~mm} / \mathrm{yr} \pm 0.4 \mathrm{~mm} / \mathrm{yr}, \mathrm{V}_{\mathrm{E}}=-9.2\right.$ $\mathrm{mm} / \mathrm{yr} \pm 0.4 \mathrm{~mm} / \mathrm{yr}$ ) and a vertical velocity $\mathrm{V}_{\mathrm{UP}}=-152.6$ $\mathrm{mm} / \mathrm{yr} \pm 1.3 \mathrm{~mm} / \mathrm{yr}$ with respect to ITRF2000. At 25 $\mathrm{km}$ from the summit of Dome C a movement with velocity of $211 \mathrm{~mm} / \mathrm{yr}$ was reported [Urbini et al. 2008, Vittuari et al. 2004].

\section{The geomagnetic observatory at Concordia Base, Dome C, Antarctica}

Geomagnetic observatories are ground based non-magnetic structures (from a simple hut to a standard brick building) aimed to collect time-series measurements of the Earth's magnetic field. Generally they are operated by academic or government institutions that voluntarily agree to disseminate collected data to scientific communities through world data centers or specific consortiums like INTERMAGNET (www.in termagnet.org). According to the guidelines issued by the IAGA (International Association of Geomagnetism and Aeronomy) organization, a geomagnetic observatory stands in a place with very low magnetized basement and surrounding environment and it produces very high quality data under some specific requirements [Jankowski and Sucksdorff 1996]. At present, of approximately 130 observatories included in INTERMAGNET only 8 are positioned beyond the Arctic and 5 beyond the Antarctic Circle (Table 1). Among these polar observatories only two are placed on the inland layered iced surface, at Vostok and Concordia stations. A monitoring point of the Earth' magnetic field can be promoted as "observatory" if the vector components and the total intensity of the magnetic field can be collected for long time with the highest accuracy and quality at a minimum sampling rate of 1-minute. The vector elements are continuously recorded above an arbitrary level which has to be adjusted by means of a baseline, derived from the manual measurements of two essential angles, the magnetic declination $\mathrm{D}$ and inclination I, and from the measurements of the total field intensity F. Those angles are measured by a fluxgate theodolite, a demagnetized optical device with a magnetometer mounted on the telescope (Figure 2), positioned over a pillar. Declination and inclination are estimated with respect to the true north by pointing 


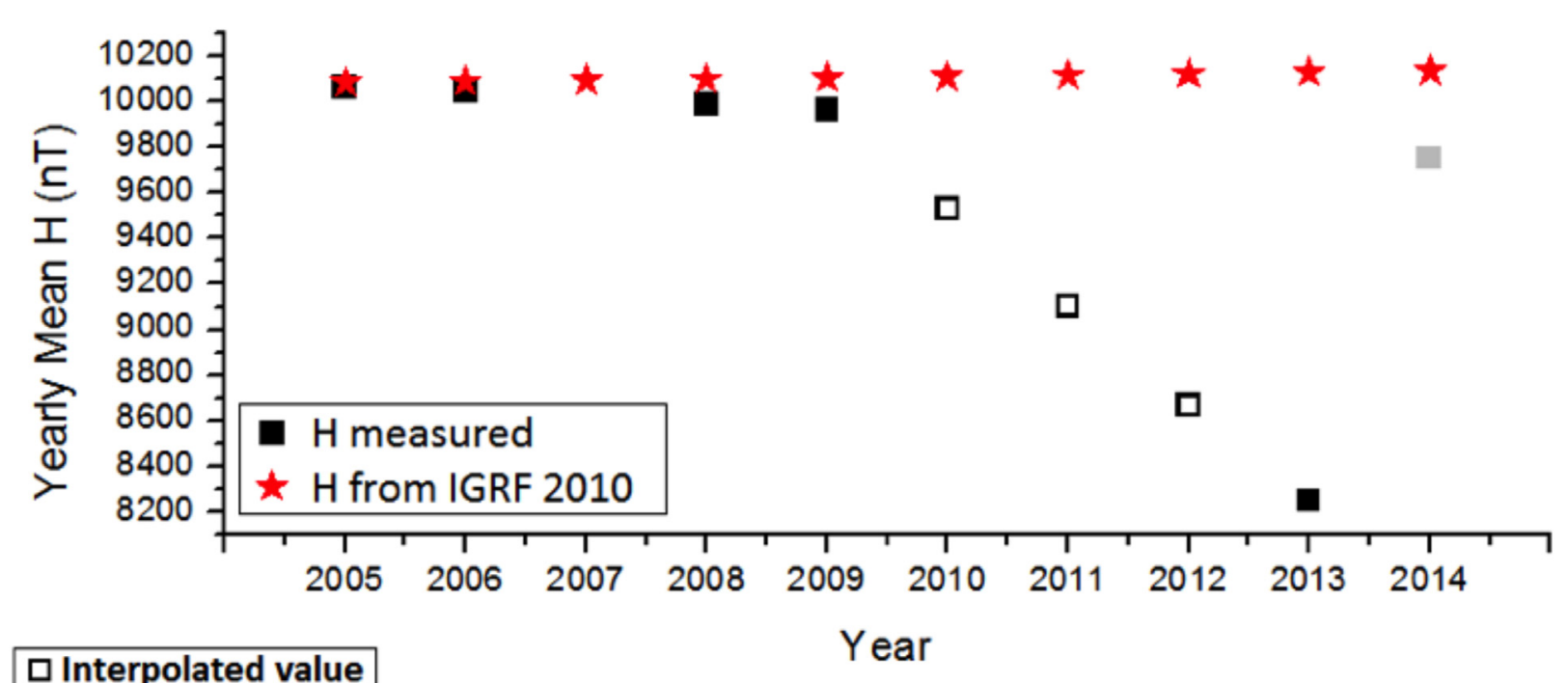

Provisional value

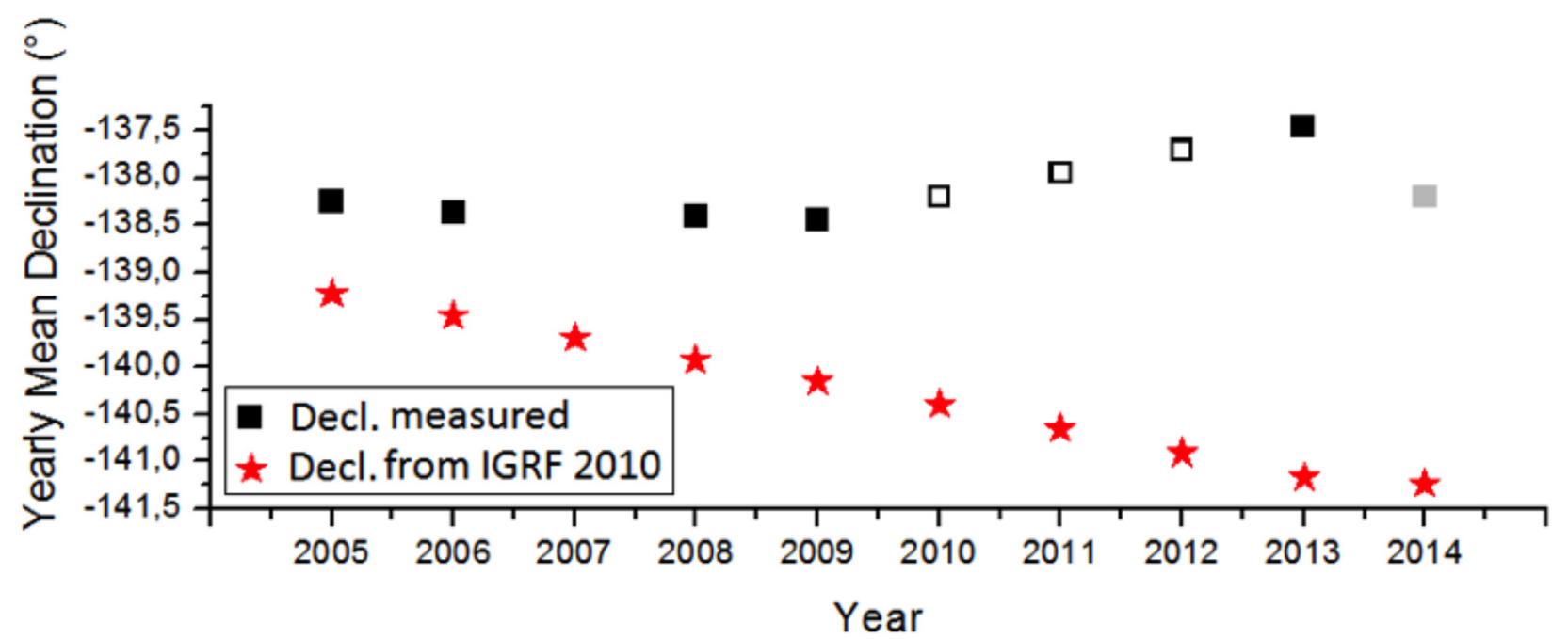

Figure 1. Comparison between the Horizontal component (top) and Declination (bottom) of the geomagnetic field from absolute measurements and from IGRF [2010] at the Concordia observatory. Values from 2010 to 2012 are linearly interpolated since observed values are under processing. Values for 2014 are provisional. Note the progressive divergence from the initial years and the inverse trend between 2013 and 2014 for both graphs. This latter trend needs to be confirmed in the future years. However, it is also important to note that in polar regions the comparison of measured geomagnetic values with those from the IGRF model is known to be somehow weak [De Santis A. et al. 2002].

the telescope towards a local azimuth mark. Both the azimuth mark and the pillar were geographically referenced. The theodolite must stand over a pillar rooted into the ground to guarantee a stability over time. Another important requirement is the stability of the room temperature where the instrumentations operate for avoiding variations due to the expansion/contraction of the mechanical parts of the instrumentation. Among the three fundamental requirements for a geomagnetic observatory, i.e. 1) continuity in data collection of $\mathrm{F}$ and $\mathrm{D}$ and I angles, 2) stability of the position of the pillar and 3) stability of the room temperature, the durable and stable position of the pillar is one of the hardest to accomplish when no rock basement is available for rooting a pillar. This is exactly the case of the Concordia station observatory. Similar conditions should be addressed in Vostok station but indi- cations of strategy to minimize their effects are not known or, at least, not found by the authors in associated literature. The magnetic observatory at Concordia station consists essentially of two amagnetic carbon fiber shelters, about $26 \mathrm{~m}$ apart, directly laying on the iced surface. One shelter hosts the automatic instrumentation, that is a vector magnetometer for the 3 components of the field recordings at $1 \mathrm{~Hz}$, and a scalar magnetometer for the total intensity of the field, with sampling rate every 10 seconds. The other shelter hosts a pillar, made of special polypropylene highly resistant against very low temperature with a marble plate on top [Schott et al. 2005]. A special crystal glass with very low refraction index, $1.5 \mathrm{~cm}$ thick, used as window, allows to optically point from the pillar toward the azimuth mark, stuck on the external wall of the shelter hosting the automatic instrumentation 


\begin{tabular}{|c|c|c|c|c|c|c|c|}
\hline $\begin{array}{l}\text { Observatory } \\
\text { Name } \\
\text { (Northern Hem.) }\end{array}$ & $\begin{array}{l}\text { IAGA } \\
\text { code }\end{array}$ & $\begin{array}{l}\text { Geog. } \\
\text { Latit. }\left(^{\circ}\right) \\
\text { North }\end{array}$ & $\begin{array}{l}\text { Geog. } \\
\text { Long. }\left(^{\circ}\right) \\
\text { East }\end{array}$ & $\begin{array}{l}\text { Elev. } \\
(\mathbf{m})\end{array}$ & $\begin{array}{c}\text { Corr. } \\
\text { Geom. Latit. } \\
(\text { IGRF 2010) }\end{array}$ & $\begin{array}{c}\text { Corr. Geom. } \\
\text { Long. EAST } \\
\text { (IGRF 2010) }\end{array}$ & $\begin{array}{c}\text { Year of } \\
\text { estab./Country }\end{array}$ \\
\hline Abisko & $\mathrm{ABK}$ & 68.36 & 18.82 & 380 & 60.114 & 114.40 & 1921 / Sweden \\
\hline Barrow & BRW & 71.32 & 166.76 & 16 & 69.72 & 246.92 & 1949/USA \\
\hline Cambridge Bay & CBB & 69.12 & 140.02 & 40 & 76.44 & 303.99 & 1972/Canada \\
\hline $\begin{array}{l}\text { Qeqertarsuaq } \\
\text { (Godhavn) }\end{array}$ & $\mathrm{GDH}$ & 69.25 & 306.47 & 0 & 78.35 & 33.76 & 1991/Greenland \\
\hline Hornsund & HRN & 77.00 & 15.37 & 15 & 73.91 & 125.26 & 2002/Norway-Poland \\
\hline Resolute Bay & RES & 74.69 & 265.10 & 30 & 82.81 & 304.69 & 1952/Canada \\
\hline Sodankyla & SOD & 67.32 & 26.63 & 178 & 64.00 & 119.79 & 1991/Finland \\
\hline Qaanaaq (Thule) & THL & 77.47 & 290.77 & 57 & 87.46 & 13.60 & 1991/Greenland \\
\hline $\begin{array}{l}\text { Observatory } \\
\text { Name } \\
\text { (Southern Hem.) }\end{array}$ & $\begin{array}{l}\text { IAGA } \\
\text { code }\end{array}$ & $\begin{array}{l}\text { Geog. } \\
\text { Latit. }\left(^{\circ}\right) \\
\text { South }\end{array}$ & $\begin{array}{l}\text { Geog. } \\
\text { Long. }\left(^{\circ}\right) \\
\text { East }\end{array}$ & $\begin{array}{l}\text { Elev. } \\
(\mathbf{m})\end{array}$ & $\begin{array}{c}\text { Corr. } \\
\text { Geom. } \\
\text { Latit. S } \\
\text { (IGRF 2010) }\end{array}$ & $\begin{array}{c}\text { Corr. Geom. } \\
\text { Long. EAST } \\
\text { (IGRF 2010) }\end{array}$ & $\begin{array}{c}\text { Year of } \\
\text { estab./Country }\end{array}$ \\
\hline $\begin{array}{l}\text { Vostok } \\
\text { (on layered ice) }\end{array}$ & VOS & $78.47^{\circ}$ & 106.82 & 3488 & 72.91 & 177.43 & 1958/Russia \\
\hline Scott Base & SBA & $77.85^{\circ}$ & 166.76 & 16 & 79.00 & 289.35 & 1957/ New Zealand \\
\hline Dumont D'urville & DRV & $66.67^{\circ}$ & 140.02 & 40 & 74.31 & 230.90 & 1956/France \\
\hline $\begin{array}{l}\text { Dome C } \\
\text { (on layered ice) }\end{array}$ & $\mathrm{DMC}$ & $75.10^{\circ}$ & 123.39 & 3233 & 87.80 & 39.17 & 2005 / Italy-France \\
\hline Mawson & MAW & $67.60^{\circ}$ & 62.88 & 12 & 73.19 & 110.94 & 1955 / Australia \\
\hline
\end{tabular}

Table 1. List of Intermagnet geomagnetic observatories located northernmost the Arctic Circle ( $66^{\circ} 33^{\prime} 44^{\prime \prime} \mathrm{N}$ ) (top frame) and southernmost the Antarctic Circle ( $66^{\circ} 33^{\prime} 44^{\prime \prime}$ S) (bottom frame). Corrected Geomagnetic Coordinates are calculated for the IGRF2010 by the online service http://omniweb.gsfc.nasa.gov/vitmo/cgm_vitmo.html. For a visualization of the position of the listed observatories on the world map visit the intermagnet website at the URL address: www.intermagnet.org. Some of these observatories, from opposite polar areas, can be considered as magnetically conjugated, that is they are linked by the same magnetic lines running from an hemisphere to the other. This aspect becomes clear when the geomagnetic coordinate reference system is taken into account. Under this condition many interesting phenomena are reported and studied (e.g. in Lepidi et al. 2011).

(Figure 2). Manual observations of the magnetic declination and inclination, called absolute measurements, are performed once a week/ten days by the staff all year round. In fact, permanent personnel is present at Dome $\mathrm{C}$ also during the long polar night, the so-called winter-overs. Besides the continuous availability of high quality data, the activity of the winter-overs for all year round and along the years within a rotation of staff, allowed the geomagnetic observatory of Dome C to become a member of the Intermagnet organization with the IAGA code of DMC in May 11, 2011. According to the initial solar observation made in summer 2003 , the azimuth between the pillar centre and the azimuth mark was at the angle $253^{\circ} 56^{\prime} 52^{\prime \prime}$ from true North. Over the years the snow accumulation forced to face the progressive coverage of the two shelters and consequently of the optical path from the pillar to the azimuth mark. Nowadays a shallow tunnel, just below the surface, is protecting this optical path from obstruction of further snow accumulation (Figure 2). The three-component field variation magnetometer and the scalar magnetometer installed at the Dome C geomagnetic observatory are described by Schott et al. [2005] and Chambodut et al. [2009]. We only recall that the vector magnetometer is a suspended triaxial fluxgate, oriented along the local geomagnetic meridian. By combining the absolute measurements taken as baselines with the variation dataset one can obtain the absolute values for each component of the Earth's magnetic field. 

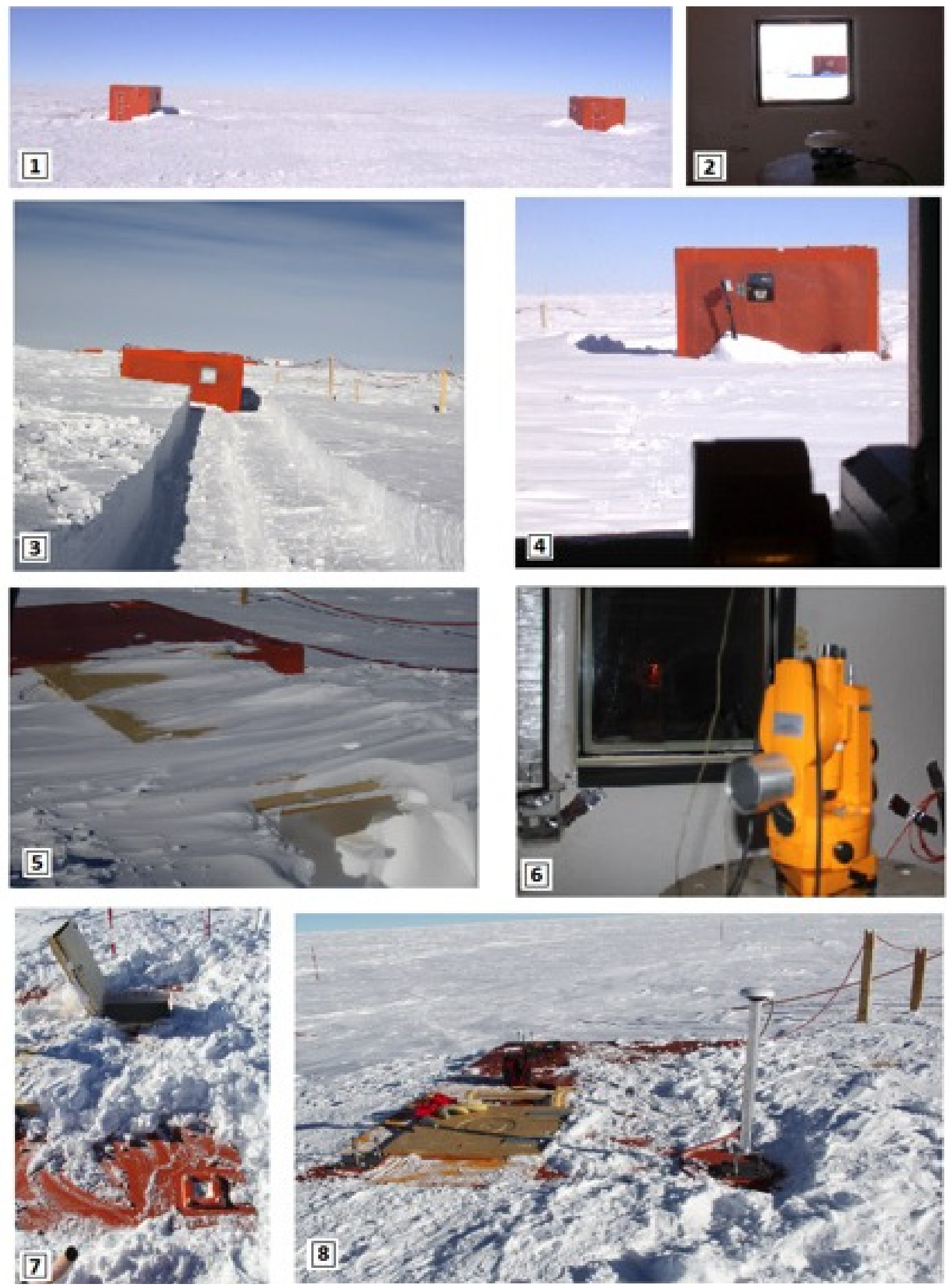

Figure 2. A compilation of pictures taken along the last decade at Concordia station. In particular: 1) Two amagnetic shelters hosting the automatic instrumentation and the pillar respectively as they appeared in 2005;2) the shelter with automatic instrumentation and azimuth mark fixed on the external wall, visible from the opposite shelter; 3) a trench in the ice facilitated some activities at the shelters and surrounding areas; 4) an enlarged view of the azimuth mark; 5) full snow coverage of one of the two shelters and wooden plates laying over the shallow tunnel (not visible). The picture was taken in 2010; 6) the dark shallow tunnel (back), the illuminated azimuth mark and the geomagnetic theodolite placed over the pillar (close-up); 7) a trapdoor mounted on the roof of one of the two embedded shelters, used as entrance; 8) new external asset for GNSS survey, in preparation for future recordings. An aluminum pole as stand for the receiver antenna screwed on top. 


\section{Snow accumulation, movement of the entire dome and GNSS surveys}

Since the establishing of the geomagnetic observatory at Concordia station, the two shelters described above, have been affected by a slow and steady coverage of snow, derived by wind transportation mechanism since the rate of precipitation at this site can be considered less effective [Scarchilli et al. 2011]. It is important to remind that every object, no matter its dimensions, from a whole station to a single electronic box, left on the iced surface becomes rapidly an obstacle for the continuous ice/snow stream and so shortly covered. For allowing a safe access to the shelters which are, at present, completely sunk in the ice, the ultimate adopted solution was to open a new entrance, a trapdoor, mounted on their roofs. The previous approach of removing large quantities of snow/ice to free the standard doors, an operation which had to be made each year, wasting time, human power and fuel for the use of snowmobiles was disregarded. A long lasting solution to avoid a rapid coverage of snow, especially applicable for large buildings, is to super-elevate the structures using an appropriate support framework (pileworks, legs or pillars) like the new buildings of Concordia station or other modern stations (Figure 3). Such solution cannot be functional for a geomagnetic observatory building because absolute measurements have to be done over a pillar firmly rooted on a fixed basement. It cannot stand suspended nor (partially) raised without any suitable protection against mechanical and/or thermal stress (wind strength and seasonal/diurnal temperature variations). The unique solution for a geomagnetic observatory based on ice, at least for the case of Concordia station, is to check and record on a regular basis both the pillar and azimuth mark geographical positions. The accuracy of the azimuth determination has a crucial and direct effect on the accuracy of declination, inclination and other derived geomagnetic quantities. In geomagnetism, different methods can be used to determine azimuths with accuracy generally from 5 to 20 " of arc, as the astronomical observations of Sun, Moon, or other celestial bodies (with accuracy of 5 " of arc or better), the gyro-theodolite (with accuracy of 15"-20" of arc) and recently the GNSS (Global Navigation Satellite System) observations (with accuracy of 5" of arc or better under specific conditions). In the case of Concordia geomagnetic observatory, after the initial determination in 2003, the progressive sinking of the two shelters did not allow any direct observation of celestial bodies. For physics-mechanical principles, the gyro-theodolite cannot provide stable measurements at such high latitude since its latitude working range is between $75^{\circ}$
$\mathrm{S}$ and $75^{\circ} \mathrm{N}$, and then not suitable for the Concordia station observatory. GNSS observations have been then used since 2005 , and the survey was repeated in 2007, 2009 and 2013. Today the GNSS includes the American GPS, the Russian GLONASS and the newborn European Galileo satellite constellations. In the near future the Chinese and Indian positioning systems will be progressively introduced. GNSS observations provide absolute and relative determination of the position of the observational points. The former is used for navigation where lower level of precision is required, while the latter is mainly used for precise positioning and geodetic studies [Šugar et al. 2012]. Moreover, positioning methods can be static or kinematic depending on the stationary or roving mode selection by the GNSS receivers, according to the purpose of the observations. The static relative survey approach was used at the geomagnetic observatory at Concordia station, along a time windows spanning 9 years. Two GPS simultaneous observations were performed by two identical $\mathrm{Navcom} \otimes$ RT-3020M dual frequency receivers which allowed to post-process baseline vectors and azimuth determination between the pillar and the azimuth mark. At Concordia station different conditions play an unfavorable role for good quality satellite signals. In the polar regions the satellite signals can be weak and unstable, this results from the orbital satellite paths that are low over the horizon of sight (elevation mask), implying a degradation or even loss of data transmission. In addition, ionospheric instabilities as scintillations [Romano et al. 2013 and references therein] might limit satellite tracking at the receivers. The Antarctic zone is outside the coverage of GNSS correction services which may help in supplying additional corrective missing data segments. The surveyed points are located indoor of both shelter and their roofs as well as the lateral walls behave as reflectors for the satellites signals producing multipath propagations to the receivers. This aspects is particularly crucial since it introduces a further rate of error in position estimation. An appropriate network of receivers and triangulation among stations were used for tying all the points of GNSS baselines together, this to minimize the errors in the azimuth determination. Postprocessing software was then used to achieve stable solution and a typical spreadsheet of results is shown in Figure 4. From an optical-geometrical point of view, the short distance between the pillar and the azimuth mark is an additional source of inaccuracy, because it enlarges the angular gap among the points of interest. Under all those limitations the results of GPS surveys are listed in Table 2. In 2005 the geographic coordinate of both the pillar and the azimuth mark allowed the determination of the azimuth mark as $253^{\circ}$ 

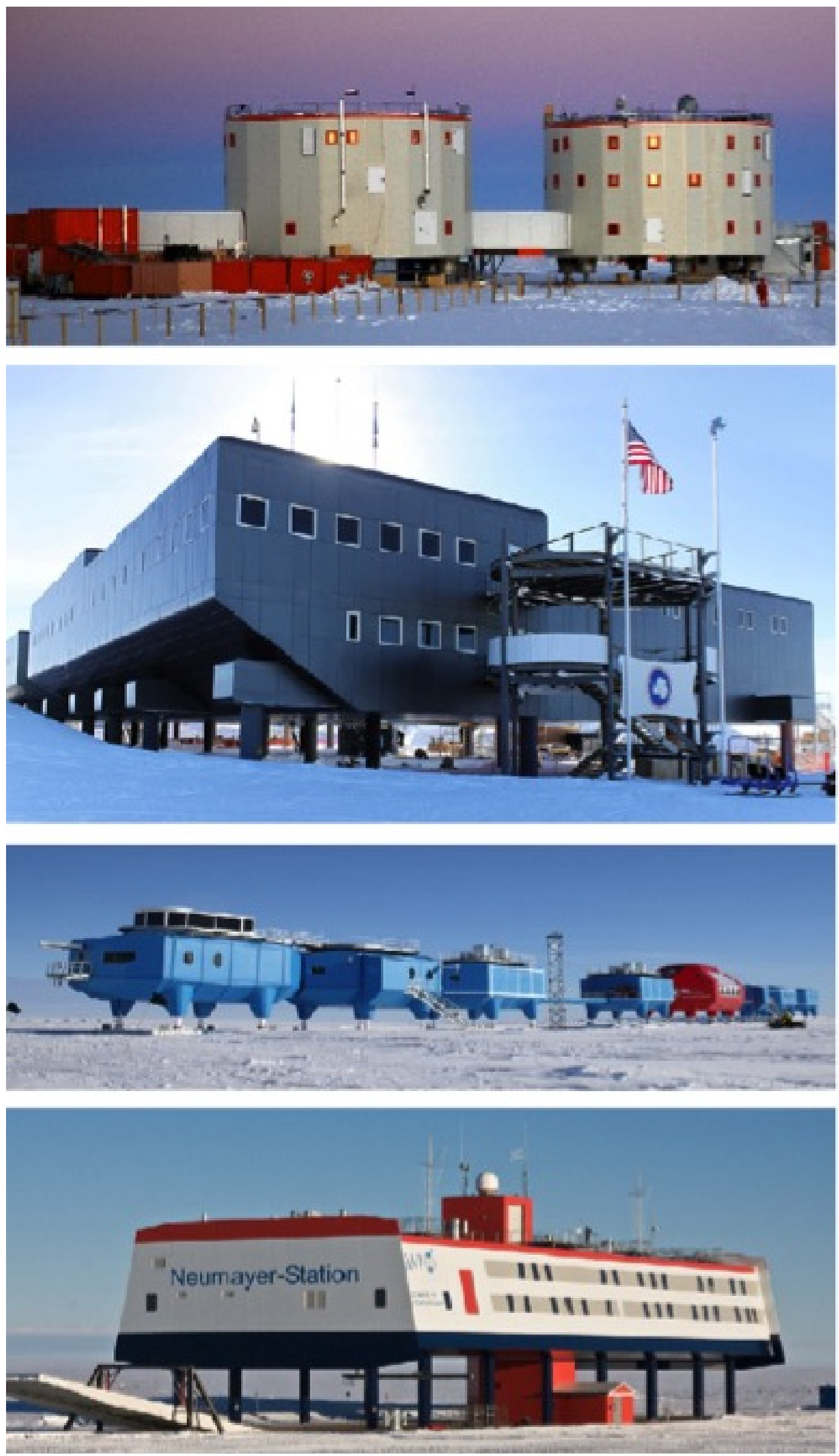

Figure 3. Four examples of modern stations erected on iced layered surface, over special legs or pillars. From top to bottom: Concordia station (Italy - France), new Amundsen-Scott South Pole station (USA), Halley VI (Great Britain), Neumayer-Station III (Germany). 
Date of survey

28Nov. 2005

Network:
1 Geodetic receiver Trimble 5700

Note:

The shelters are on the iced surface
Point

LAT.

(WGS84)

DMS
LONG.

(WGS84)

DMS
Horizontal

Standard

Deviation (mm)

$\begin{array}{llll}\text { Pillar P1 } & -75^{\circ} 06^{\prime} 8.88^{\prime \prime} & 123^{\circ} 19^{\prime} 59.01^{\prime \prime} & +-10 \\ \text { Mark M1 } & -75^{\circ} 06^{\prime} 9.11^{\prime \prime} & 123^{\circ} 19^{\prime} 55.88^{\prime \prime} & +-10\end{array}$

AZIMUTH (from Pillar to MARK): $253^{\circ}$ 54' 24.4"

RMS (31 mm), SD (1.9 mm)

Difference to initial azimuth: -2' 27.6"=-147.6"

Horizontal distance on ellipsoid: $26.001 \mathrm{~m}$

Surface distance on geoid: $26.014 \mathrm{~m}$

Free air distance: $26.015 \mathrm{~m}$

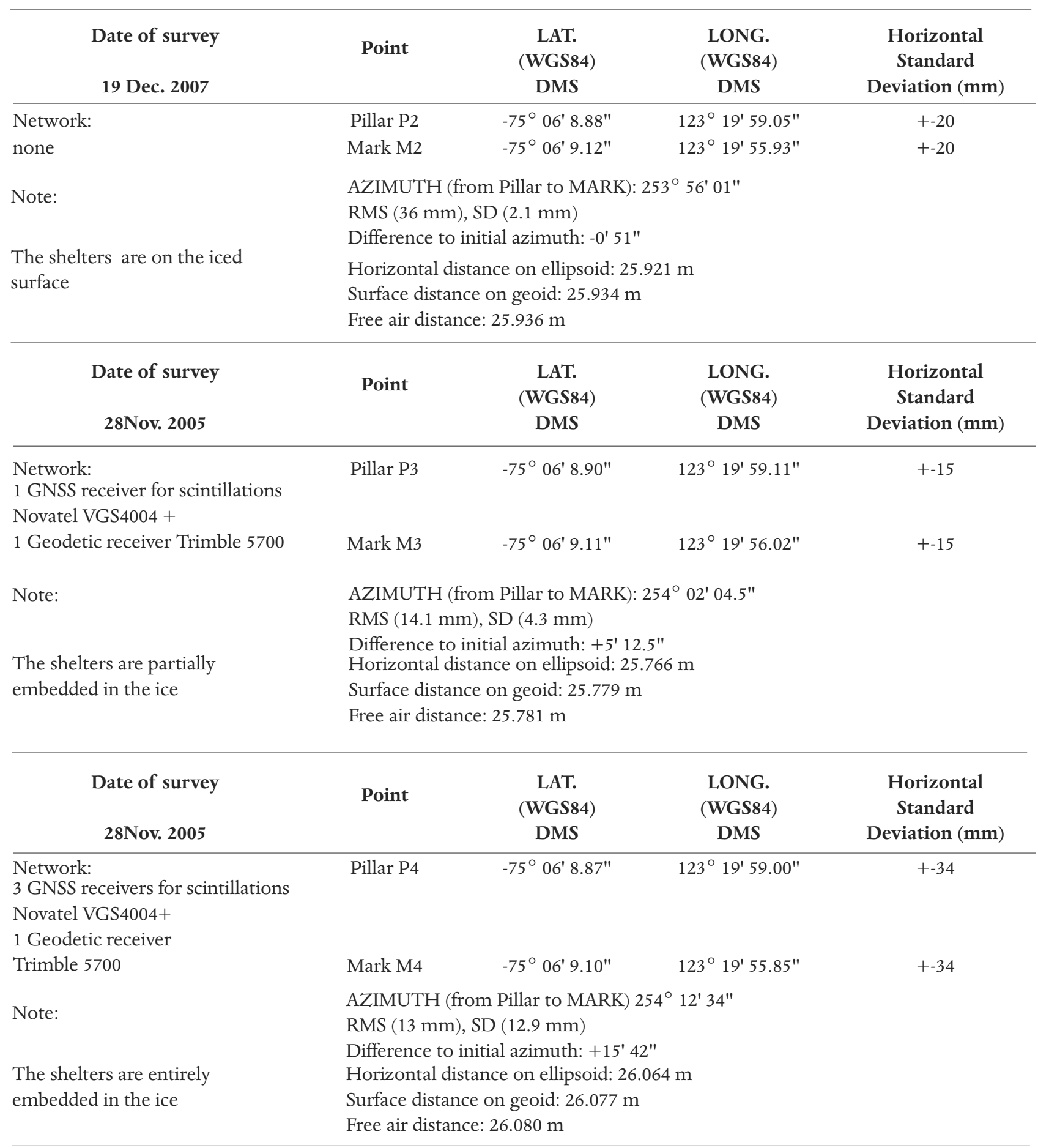

Table 2. Summary results for positioning surveys performed in 2005, 2007, 2009 and 2013 (from top to bottom) aimed to determine precise angular direction between the pillar and the azimuth mark at Concordia geomagnetic observatory. 


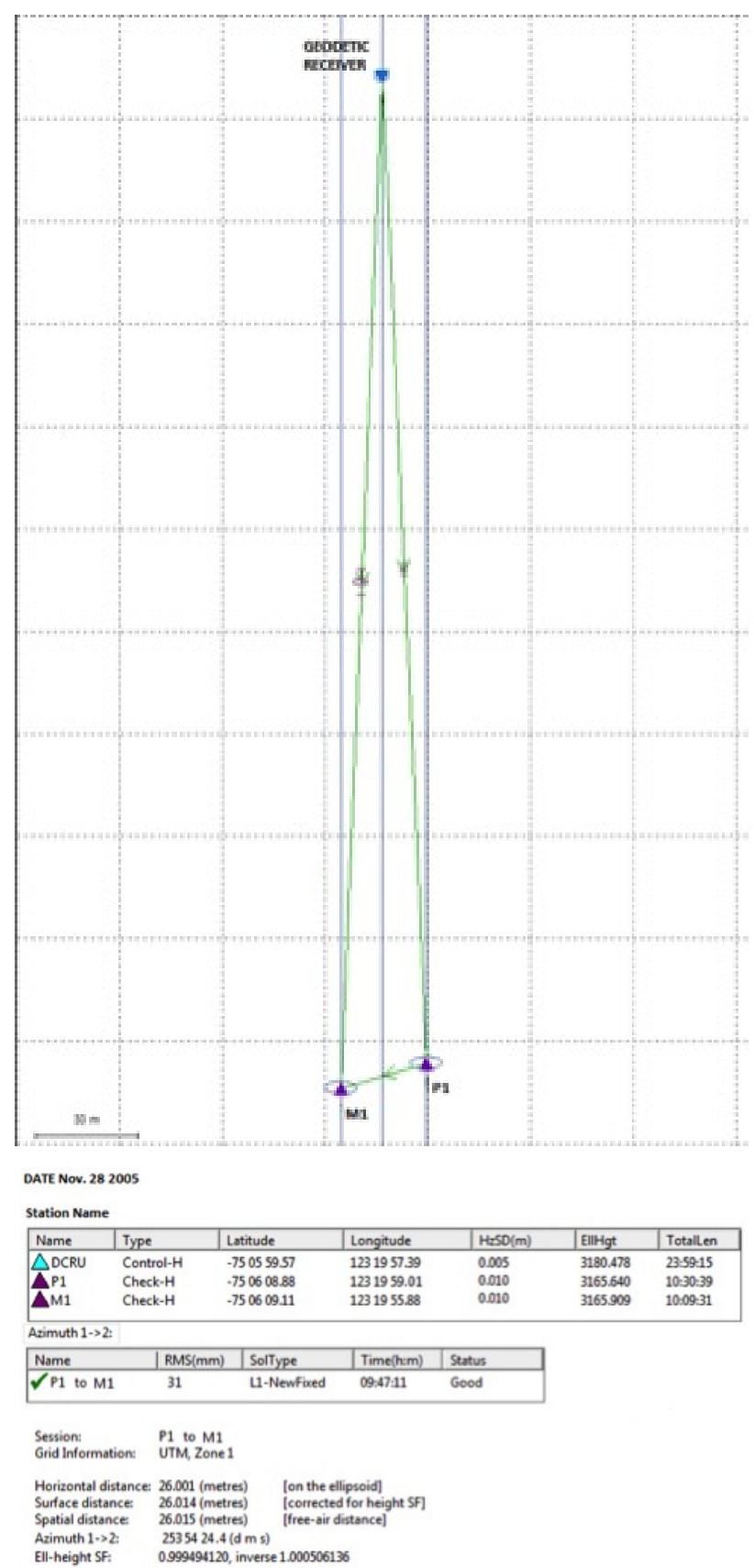

Figure 4. Graphic and computer results of a GNSS survey carried out in Nov. 28, 2005. P1 and M1 indicate geographic positions of the pillar and azimuth mark, respectively.

54' 24.4" (RMS=31 mm), the measure was close to the value obtained in 2003 via astronomical observations with a difference of $-147,6$ " of arc towards South (negative difference, see Table 2). At the time of that observation only the dataset from one additional geodetic GPS receiver was available. This permanent point, equipped with a Trimble 5700, is still working and positioned on the roof of the southernmost building at Concordia station. For a target $30 \mathrm{~m}$ distant, a deviation of $\pm 10 \mathrm{~mm}$ corresponds to an angular width of $\pm 60^{\prime \prime}=1^{\prime}$ of arc. Assuming the moderate threshold of \pm 20 " of arc achievable with a gyro-teodolite as an acceptable accuracy for the azimuth determination, during the 2005 measure this limit was overcome by a factor of 9 (RMS $=31 \mathrm{~mm}$ associated to the azimuth determination). In 2007 the unavailability of the permanent GPS receiver determines a poorer accuracy with a deviation of $\pm 36 \mathrm{~mm}$. A lower level of error was achieved in 2009 when, besides the permanent receiver, an additional dataset was available in the framework of a project aimed to ionospheric scintillation observations via one GPS recordings (Novatel VGS4004). In 2009 the shelters were partially embedded into the ice. Despite the availability of 3 identical GPS receivers (Novatel VGS4004) operating at 3 different points of the base and the availability of permanent receiver dataset generating a robust network of points for crossed triangulations, in 2013 the complete embedding of the shelters into the ice caused a standard deviation of $\pm 34 \mathrm{~mm}$ in the position of each single point (Pillar P4, Azimuth mark M4 in Table 2) but a better accuracy in the azimuth determination. For this last determination a final difference of $+15^{\prime} 43^{\prime \prime}$ of arc towards North (positive difference) from the initial value was found. In 2009 and 2013 two direct measurements of the distance in free air between the pillar centre and the azimuth mark were executed with tape meter and laser meter, respectively. In the first case the total distance was m 25.76 \pm 0.01 (November 2009), very close to the horizontal distance on ellipsoid, and in the second case was m 25.729 \pm 0.001 (November 2013). In the limit of the correctness of a free air measurement performed manually outdoor in 2009 and assuming the superior intrinsic precision of the procedure with laser meter, the distance from the pillar to the azimuth mark decreased of about $3 \mathrm{~cm}$ in 4 years. The two shelters consequently are moving and getting closer. Despite the inaccuracy of each measure shown in Table 2, a directional evolution for the different azimuths is observed (Figure 5). The limit of the computed errors cannot allow any quantitative indication on the strength of the global displacement. In fact, note that the free air distance between the pillar to the azimuth mark, from the 2009 to 2013 GNSS observations is increased by $30 \mathrm{~cm}$ which is not realistic and does not validate the laser measurement. Nevertheless, this analysis shows that both shelters are almost coherently moving along the years. From the first azimuth determination (line 1 in Figure 5) to the third determination (line 3) a displacement toward SE and a slight rotation clockwise are shown along the time interval 2005-2009. An opposite direction is visible in the transition from the third to the fourth and last determination (2009-2013) along the direction NNW (about $340^{\circ}$ from north), comparable to the result from geodetic studies (direction $302^{\circ}$ ). It is also interesting to remark that the last azimuth mark position M4 (2013) is getting closer to the first position M1 


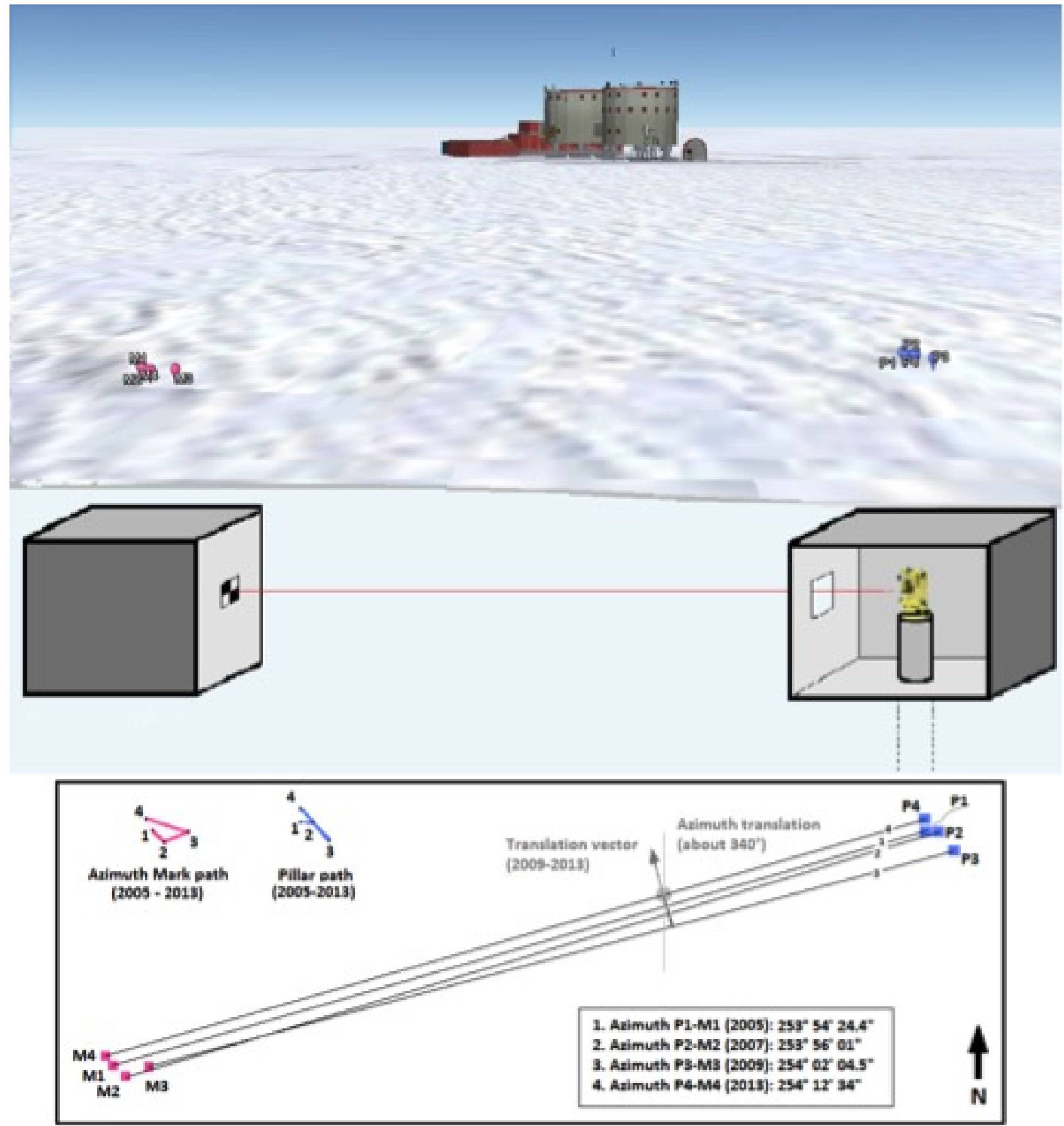

Figure 5. Graphic rendering (from Google Earth TM) of Concordia Station and the evolution of the geographic positions for the pillar (P1 to P4) and azimuth mark (M1 to M4), in successive GNSS surveys from 2005 to 2013, together with a schematic sketch of the current configuration of the whole observatory (middle figure). Both shelters are completely embedded into the ice at present. Each azimuth line is reported from 1 to 4 (bottom graph), according to the year of survey. A translation along the years in two opposite directions and slight rotations are reported also in the text. In the left side, the complete path followed by the azimuth mark position along the years resembles a nearly close loop.

(2005), in a sort of almost closed loop as shown in corresponding path of figure 5 (bottom graph, left side). This last condition may explain the reduced divergence between the measured values of $H$ and $D$ and those from IGRF (Figure 1), which is evident since 2013 and future observations are needed to follow up this trend. This behavior is due to the fact that relative rotation between pillar and azimuth mark has a stronger effect on the horizontal component and declination, both very sensitive to angular deviations along the years from a stable configuration. The progressive increasing of error associated to the azimuth determination via GNSS observations over the years is certainly due to the progressive sinking of the observatory. The current situation cannot allow to run further indoor measurements, being currently the shelters fully incorporated into the ice. Generally the condition to operate under a layered and compact ice coverage makes any aspiration to have good quality GNSS dataset fruitless, at least at very high latitudes. At Concordia, the recently defin- 
itive solution adopted for retrieving GNSS data with low rate of degradation consisted in installing some suitable points of observation joint to the roof of the two shelters which are at the same level of the free iced surface (Figure 2, sub-picture 8). GNSS measurements will be repeated at least once per year, and the additional contributions from frequent verification of the relative distance and rotation between the pillar position and azimuth mark will be tested in the coming years for getting a corrective term to the geomagnetic dataset. Considering the prudent approach to assume that the entire effect of the measured movement of the system (azimuth mark and pillar position), whose incidence is within the order of few minutes ( $\left.\max 15^{\prime}\right)$ of degree over the years, we can only partially explain the observed features in the declination values, since the deviation seen with respect the IGRF model is within a range of 2-3 degrees. Investigations and longer series of data are needed to better understand such behavior over the future years.

\section{Discussion}

Differently from any scientific installations rooted on solid ground thus subjected only to plate tectonic movements as first order of magnitude, generally negligible in geomagnetism, any point of observation laying on layered iced surface may suffer from additional source of displacement mainly due to ice movement. From place to place, local movements strongly influenced by topographic asset and other glaciological dynamics, are detectable. This additional contribution can be relevant and cannot be disregarded especially if issue of position of an object is a fundamental parameter to derive other quantities. This is exactly the case of the geomagnetic observatory established at Concordia station, Dome $\mathrm{C}$ on the Antarctic plateau. To avoid biases in the recordings of geomagnetic quantities an occasional monitoring of the pillar and the azimuth mark positions was adopted at Concordia observatory via GNSS observations to track their spatial migrations along the years. No point of a floating/shifting system can be used as reference for local positioning unless monitored by GNSS system or by other absolute positioning methods. Any referenced point will be completely defined, giving the absolute geographic coordinates so derived and the date of the surveyed position, since they may change over time. At the Concordia geomagnetic observatory the growing rate of error to the azimuth determination via GNSS technique is due to the progressive sinking of the observatory, bringing to disregard any further indoor data collection since the shelters are sunk in the ice. The
GNSS signal degradation is strongly reduced when the displacement is monitored from the free iced surface above the shelters. Some permanent points joint to the shelters have been recently selected and arranged in a way that GNSS measurements can be routinely repeated. A permanent GNSS station and a number of additional (temporary) receivers are necessary to generate a network of control points for a robust approach to the computation of a reliable determination of positions. The further contribution from direct measurements of the relative distance and rotation between the pillar position and azimuth mark will be also inspected in the coming years together with a reliable GNSS determination of mutual positions aimed at establishing corrective terms which may effectively counterbalance the real migration of the observed displacements and their effects on geomagnetic dataset.

Acknowledgements. Luca Vittuari and Vincenzo Romano are acknowledged as data provider of GNSS recordings. Andrea Piancatelli is thanked for the GNSS survey in 2007. EOST (École et Observatoire des Sciences de la Terre, France), INGV (Istituto Nazionale di Geofisica e Vulcanologia, Italy), IPEV (Institut Polaire Paul Émile Victor) and PNRA (Programma Nazionale per le Ricerche in Antartide) are also acknowledged for their scientific and logistics support and contributions to the maintaining of the geomagnetic observatory at Dome C. Pascal Bordais, Jean-Francois Vanacker, Lucia Angioletto, Jonathan Zaccaria, Erick Bondoux, Antonio Litterio and Paride Legovino are thanked for their geomagnetic observational activities during the winter seasons from 2005 to 2014.

\section{References}

Akasofu, S.-I. (2002). Exploring the Secrets of the Aurora, Kluwer Academic Publishers, Netherlands.

Capra, A., and R. Dietrich (Eds.) (2008). Geodetic and Geophysical Observations in Antarctica, SpringerVerlag Berlin.

Chambodut, A., D. Di Mauro, J. J. Schott, P. Bordais, L. Agnoletto and P. Di Felice (2009). Three years continuous record of the Earths' magnetic field at Concordia station (DomeC, Antarctica). Annals of Geophysics, 52, 15-24.

De Santis, A., J. M. Torta, and L. R. Gaya-Piqué, (2002). The first Antarctic geomagnetic Reference Model (ARM), Geophys. Res. Lett., 29(8), doi:10.1029/2002GL014675.

Jankowski, J. and C. Sucksdorff (1996). Guide for magnetic measurements and observatory practice, International Association of Geomagnetism and Aeronomy, Boulder (USA), pp. 235.

Lepidi, S., L. Cafarella, M. Pietrolungo and D. Di Mauro (2011). Daily variation characteristics at polar geomagnetic observatories, Adv. Space Res., 48, 521-528.

Rignot, E., J. L. Bamber, M. R. van den Broeke, C. Davis, Y. Li, W. J. van de Berg and E. van Meijgaard (2008). Recent Antarctic ice mass loss from radar in- 
terferometry and regional climate modelling, $\mathrm{Na}$ ture Geosci, 1, 106-110, doi:10.1038/ngeo102.

Romano V., G. Macelloni, L. Spogli, M. Brogioni, G. Marinaro and C. N. Mitchell (2013). Measuring GNSS ionospheric total electron content at Concordia, and application to L-band radiometers. Annals of Geophysics, 56 (2), R0219, doi: 10.4401/ag-6242.

Scarchilli, C., M. Frezzotti and P.M. Ruti (2011). Snow precipitation at four ice core sites in East Antarctica: provenance, seasonality and blocking factors, Clim. Dyn., 37, 2107-2125, doi:10.1007/s00382-010-0946-4.

Schott, J.J., D. Di Mauro, A., Peres, L., Cafarella, L. Magno, A. Zirizzotti and A. Meloni (2005). Towards the opening of a magnetic observatory at DomeC (Antarctica), Proceedings XIth Workshop on Geomagnetic Observatories, Instruments, Data Acquisition and Processing, (Kakioka, November 17-24, 2004)

Šugar, D., M. Brkić and D. Špoljarić (2012). Comparison of the reference mark azimuth determination methods, Annals of Geophysics, 55 (6), 1071-1083; doi: $10.4401 /$ ag- 5405.

Urbini S., Frezzotti M., Gandolfi S., Vincent C., Scarchilli C., Vittuari L. and Fily M. (2008) Historical behaviour of Dome C and Talos Dome (East Antarctica) as investigated by snow accumulation and ice velocity measurements. Global and Planetary Change. Vol $60 / 3-4$ pp 576-588 DOI: 10.1016/j.gloplacha.2007.08.002.

Vittuari, L., Vincent, C., Frezzotti, M., Mancini, F., Gandolfi, S., Bitelli, G. and Capra, A. (2004). Space geodesy as a tool for measuring ice surface velocity at the Dome C site and between Terra Nova Bay and Dome C (East Antarctica), Ann. Glaciol. 39, 402-408.

\footnotetext{
${ }^{\star}$ Corresponding author: Domenico Di Mauro, Istituto Nazionale di Geofisica e Vulcanologia, Rome, Italy; email: domenico.dimauro@ingv.it. 